\title{
Decadal-scale dynamics of sea urchin population networks in Fiordland, New Zealand are driven by juxtaposition of larval transport against benthic productivity gradients
}

\author{
Stephen R. Wing* \\ Department of Marine Science, 310 Castle Street, University of Otago, Dunedin 9054, New Zealand
}

\begin{abstract}
Size structure among 3 genetically distinct populations of the sea urchin Evechinus chloroticus was investigated between 1998 and 2007 at 22 study sites distributed in the Fiordland region in southwestern New Zealand. Data on morphology and abundance of the common kelp Ecklonia radiata was used as an indicator of the availability of high-quality food among sites. Habitats close to the fjord entrances with relatively high density of $E$. radiata $\left(0.5 \pm 0.1\right.$ [SE] to $\left.1.2 \pm 0.2 \mathrm{~m}^{-2}\right)$ supported E. chloroticus subpopulations with large average test diameters among years $(94 \pm 9.3$ to $120 \pm 2.8 \mathrm{~mm}$ ) and stable adult modes across the $10 \mathrm{yr}$ period. In contrast those subpopulations in inner fjord habitats with lower E. radiata abundance $\left(0\right.$ to $\left.0.4 \pm 0.1 \mathrm{~m}^{-2}\right)$ were characterised by smaller average test diameters $(64.3 \pm 6.5$ to $103.4 \pm 1.7 \mathrm{~mm})$ and frequent large pulses of newly emergent juveniles $(<60 \mathrm{~mm})$. These patterns in demographic variability were apparent in an index of recruitment, which increased from the kelp-dominated outer coast to the marginal inner fjord habitats. In the $10 \mathrm{yr}$ period, complete adult mortality events were observed at 5 sites in inner fjord habitats, followed by re-colonisation by newly emergent juveniles. The data suggest that population networks arranged across gradients of habitat quality are more likely to exhibit rescue effects and to maintain higher abundance in marginal habitat than are isolated populations. These results highlight the importance of including core source populations in marine reserve networks for regional persistence and stability of marine metapopulations.
\end{abstract}

KEY WORDS: Fiordland $\cdot$ Marine reserve $\cdot$ Metapopulation $\cdot$ Sea urchin $\cdot$ Sources $\cdot$ Sinks Resale or republication not permitted without written consent of the publisher

\section{INTRODUCTION}

Many coastal marine populations are made up of networks of discrete subpopulations of relatively sedentary adults linked by larval dispersal at the mesoscale (10 to $100 \mathrm{~km}$ ) (Hixon et al. 2002, Kritzer \& Sale 2006). Patterns in abundance, and structure of population networks at this scale are strongly influenced by the interaction between hydrodynamic forcing of larval dispersal with patterns in adult productivity and larval production. Consequently, understanding relationships between coastal circulation and recruitment processes has been the focus of a wide range of ecolog- ical studies on marine invertebrates and fishes (McEdward 1995, Morgan 2001, Underwood \& Keough 2001). In this context, several studies have highlighted the structural importance of coastal topography and retention of larvae within the coastal boundary layer (Ebert \& Russell 1988, Morgan et al. 2000, Diehl et al. 2007), and the dispersal of larvae within island systems or among estuaries (Jones et al. 1999, Hughes et al. 2000, Almany et al. 2007). These studies have led to considerable insight on the spatial scale of variability within coastal population networks and highlighted the importance of connectivity as a population structuring mechanism in these systems (Fogarty \& Botsford 2007). 
The resulting regional-scale population dynamics and persistence within this class of populations is therefore strongly driven by interactions among subpopulations in terms of the source and supply of new recruits and also by spatial variability in vital rates of adults (Wing et al. 2003, Sanford \& Menge 2007).

This issue is particularly apparent in topographically complex regions. One such environment is Fiordland, New Zealand where the 15 fjords represent an insular array of marine habitats. Within each fjord there are strong gradients in benthic productivity from abundant kelp forests in the wave-exposed outer coastal habitats to the quiescent inner fjord regions where forest litter dominates the organic matter pool (McLeod \& Wing 2007, Wing et al. 2008). This gradient in the quantity and quality of food resources for benthic grazers such as the sea urchin Evechinus chloroticus (Echinodermata: Echinoidea) within each fjord creates the basis for strong bottom-up controls on growth and reproductive output of adults (Wing et al. 2003, 2008). Mean estuarine circulation driven by a distinct freshwater layer in each of the fjords tends to transport larvae away from relatively fecund populations at the entrances of the fjords towards the less productive habitats in the inner fjords, which results in abundant settlement of E. chloroticus in habitats that are marginal for adult growth and survival (Lamare 1998, Wing et al. 2003).

Evechinus chloroticus is endemic to New Zealand and as a subtidal grazer, it has a critical influence on both the composition and productivity of coastal kelp forests and algal reefs (Choat \& Schiel 1982, Choat \& Andrew 1986, Shears \& Babcock 2002). Its distribution includes the Snares, Stewart Island, Chatham Island and Three Kings Islands as well as the mainland North and South Islands (Pawson 1965, Dix 1970b). Dispersal is limited to planktonic drifting and weak ciliary swimming of planktotrophic echinopluteus larvae, which are produced annually with a pelagic existence of 1 to 2 mo (Dix 1969, 1970a, Walker 1984). Juveniles of less than 40 to $50 \mathrm{~mm}$ test diameter are usually cryptic, living in rock crevices and under boulders until they emerge as new recruits into the adult population (Shears \& Babcock 2002). Within these habitats, growth may be slower and more consistent than among the adult population (Lamare \& Mladenov 2000). Because recruitment is typically sporadic and potentially driven by larval supply from distant populations along the coast, the spatial distribution of populations is a critical feature of their regional dynamics.

In Fiordland, the effect of estuarine circulation on larval dispersal may result in reproductive isolation of populations within some fjords and strong variability in larval supply across the remaining population network (Wing et al. 2003, Perrin et al. 2004). Using microsatellite markers, Perrin et al. (2003) identified 2 distinct ecotypes of Evechinus chloroticus in Fiordland. Ecotype A was restricted to the most wave-exposed habitats on the outer coast and genetically contiguous with other populations around the South Island. Ecotype B was found at fjord entrance sites and in the inner fjord habitats. Further, within Ecotype B, the population in Long Sound was found to be genetically distinct and it is likely that sea urchin larvae rarely disperse into or out of this fjord (Perrin et al. 2003). Therefore, the E. chloroticus population in Fiordland consists of 3 distinct classes of populations (Fig. 1). Ecotype A represents an 'open' population with open larval exchange along the coast (Fig. 1d). Ecotype B represents a population network, with satellite populations in the inner fjords (Fig. 1b) linked by larval exchange with populations distributed among entrance sites (Fig. 1a). Finally, the geographically isolated population in Long Sound represents a self-seeding population within Ecotype B (Fig. 1c).

This highlights the interesting question of how these 3 different types of populations (open, isolated, network) are forced by environmental influences on adult growth, survival and recruitment to produce patterns in population structure and abundance. In the present study, the size structure of Evechinus chloroticus populations was examined for multiple events over $10 \mathrm{yr}$ from 22 sites distributed across the Fiordland landscape. Measurements of the variability in morphology and abundance of the common kelp Ecklonia radiata were used to indicate availabiliy of high-quality food among sites (Wing et al. 2007). Repeated measurements of size distributions of sea urchins were used to investigate demographic variability, as indicated by an index of recruitment, and by variability in average test

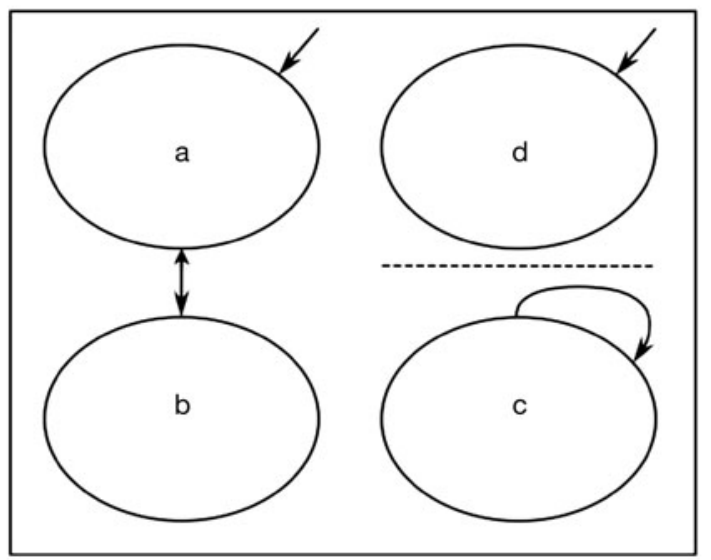

Fig. 1. (a) A core population and (b) a satellite population in a population network; (c) an isolated self-seeding population and (d) an open population. The dashed line indicates a restriction in dispersal; arrows represent larval dispersal among subpopulations 
diameter among sites across the region. These data were analysed to test regional patterns in population structure and dynamics across Fiordland with reference to (1) availability of high-quality food, (2) position within the fjords and (3) genetic subdivision of populations within the region. Results of these analyses offer a test of how juxtaposed patterns in recruitment and habitat quality interact to structure and maintain distribution and abundance within and among the 3 populations across this region. This issue has important application to understanding how the newly implemented marine reserve network in Fiordland may influence populations and communities in the system, and specifically how dynamics of subpopulations within marine reserves can be strongly influenced by local habitat quality and by connectivity to populations outside of the reserve network.

\section{MATERIALS AND METHODS}

Sea urchin size structure. Size structure information on sea urchins Evechinus chloroticus was collected using SCUBA during Fiordland-wide surveys in 1998, 1999, 2002, 2003, 2004, 2005 and 2007 (Fig. 2). The 22 sites were surveyed at least 4 times over this time period (Table 1). Care was taken at each site to collect all sea urchins in a swath 0 to $20 \mathrm{~m}$ depth along the shore for 50 to $200 \mathrm{~m}$, depending on density, and search for cryptic juveniles in rubble fields and crevices. At each site, test diameter was measured with Vernier calipers to the nearest $\mathrm{mm}$, and the sea urchins were returned to the seabed. Yearly sample sizes among the 22 sites ranged from 12 to 499 (mean $\pm \mathrm{SE}$, $149 \pm 9$ ) and reflected a haphazard accumulation of individuals from each population (Table 1).

Average test diameter $(\mathrm{mm})$ from each of the resulting size distributions and average 'adult' test diameter, individuals $>60 \mathrm{~mm}$, were calculated by year and among years for each study site, and SE calculated among years. A recruitment index of the fraction of newly emergent juveniles in the population, animals $<60 \mathrm{~mm}$ test diameter (Morgan et al. 2000), was calculated for each site and year and an average and SE was calculated among years.

Average size frequency was calculated among years for each site, with $\mathrm{SE}$ within each $5 \mathrm{~mm}$ size class among years. The average distributions were combined within Ecotype A sites, and within the population network (Ecotype B) for sites from fjord entrance habitats and sites from inner fjord habitats, and for Long Sound. The resulting distributions correspond to population units and major habitat divisions identified by Perrin et al. (2003), with SE among sites stratified among years.

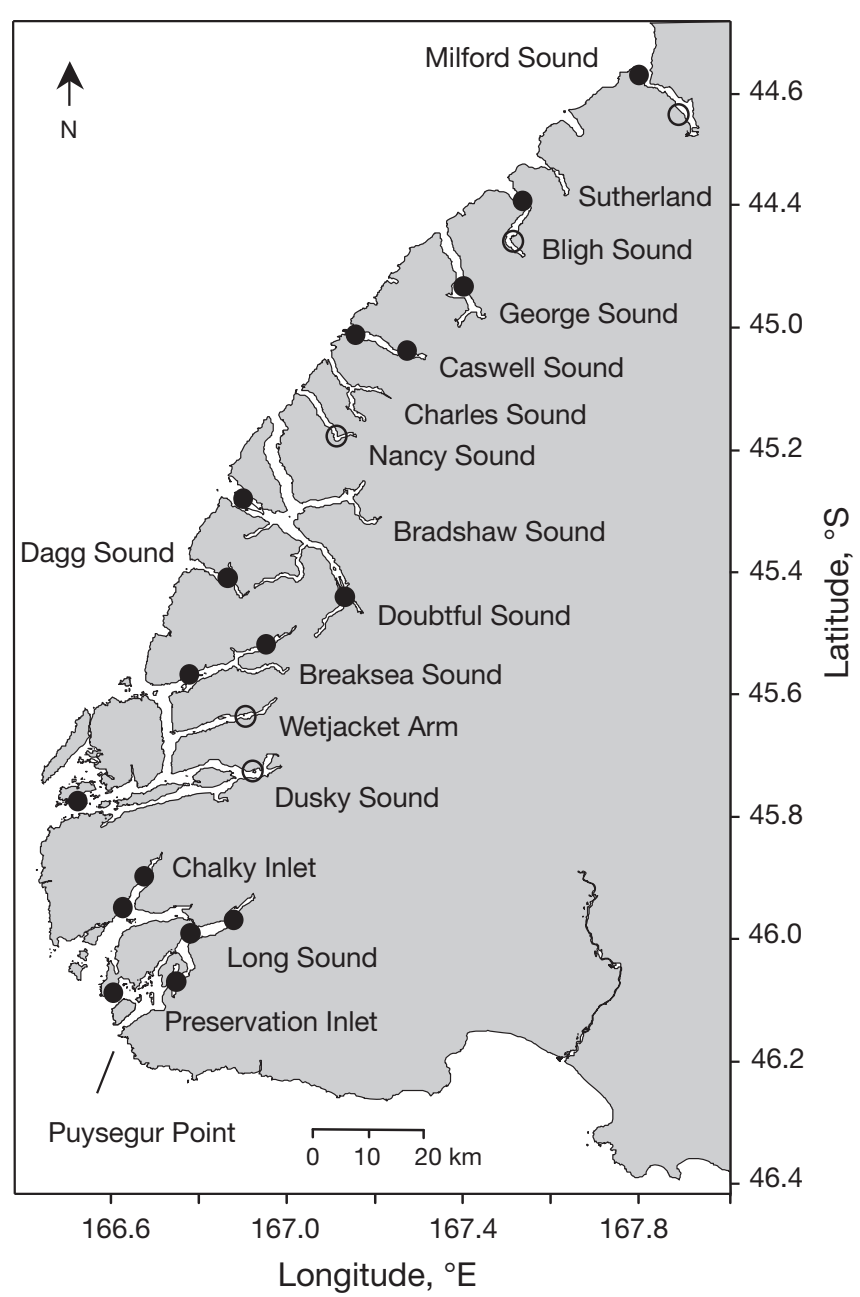

Fig. 2. Distribution of 22 study sites in Fiordland. O: 5 sites where adult mortality events were observed

Ecklonia radiata and Evechinus chloroticus abundance survey. A stratified random survey was conducted using $2 \mathrm{~m}^{2}$ quadrats at depths of 5, 10 and $15 \mathrm{~m}$ during Fiordland-wide surveys in 2003, 2004 and 2006. At each stratum a series of 6 paired quadrats was quantified for E. chloroticus, the common kelp E. radiata and other conspicuous species of brown algae. For both kelps and sea urchins, if an organism was located on the border of the quadrat, it was counted. At each quadrat position, the first lay of the quadrat was quantified and then the quadrat was flipped horizontally at the same depth stratum for a second count. This resulted in a series of 6 replicate $4 \mathrm{~m}^{2}$ quadrats at each depth stratum. Four $\mathrm{m}^{2}$ is an appropriate spatial scale for this type of sampling because it averages across a large enough area to resolve local density patterns (Wing et al. 2003). Average density of E. radiata at 21 survey sites that matched those with size structure information was calculated among the 3 surveys. 
Table 1. Sample sizes for size distribution time series by site and survey. Sites in Ecotype A are in italics, those in Long Sound are in bold, the remaining sites are made up of Ecotype B. Within Ecotype B, sites are designated according to habitat, inner and outer (see Fig. 8)

\begin{tabular}{|c|c|c|c|c|c|c|c|}
\hline Site & Apr 1998 & Apr 1999 & Oct 2002 & Nov 2003 & Nov 2004 & Nov 2005 & Feb 2007 \\
\hline Milford inner & 308 & 59 & 205 & & & 252 & 134 \\
\hline Milford outer & & 50 & 144 & & & 159 & 110 \\
\hline Bligh outer & & 116 & 90 & 73 & & 148 & 103 \\
\hline Bligh inner & & 35 & 262 & 54 & & 167 & 124 \\
\hline George & 210 & 50 & 52 & 57 & & 92 & \\
\hline Caswell inner & 289 & 91 & 185 & 114 & & 229 & 119 \\
\hline Caswell outer & & 104 & 101 & 101 & & 135 & 120 \\
\hline Nancy inner & 340 & 50 & 135 & 102 & & 321 & 103 \\
\hline Doubtful inner & 197 & 372 & 158 & & & 210 & 127 \\
\hline Doubtful outer & 418 & 219 & 125 & & & 127 & 117 \\
\hline Dagg & 223 & 50 & 106 & 65 & 93 & 100 & 112 \\
\hline Breaksea inner & 499 & 94 & 55 & 41 & 12 & 60 & \\
\hline Breaksea outer & 185 & 84 & 138 & 37 & 136 & 167 & 95 \\
\hline Wetjacket & 177 & 50 & 70 & 27 & 88 & 454 & 118 \\
\hline Dusky inner & 106 & 28 & 132 & 86 & 232 & 298 & \\
\hline Dusky outer & 391 & 50 & 117 & 96 & 52 & 83 & 112 \\
\hline Chalky inner & & 50 & 180 & & 183 & 251 & 138 \\
\hline Chalky outer & 492 & 50 & 118 & & 147 & 223 & 129 \\
\hline Long inner & 125 & 108 & 32 & 94 & 304 & 315 & 110 \\
\hline Long outer & & & 175 & & 76 & 89 & 54 \\
\hline Long entrance & & & 256 & & 220 & 207 & 123 \\
\hline Preservation outer & 418 & 99 & 235 & & 117 & 195 & \\
\hline
\end{tabular}

Morphology of Ecklonia radiata. During Fiordlandwide surveys in 2002, 2003 and 2004, morphological data were collected at 5, 10, 15 and $20 \mathrm{~m}$ at 17 sites where E. radiata was present. Five to 7 mature E. radiata individuals were haphazardly collected from each study site and depth. For each individual, frond length and width, stipe length and diameter, secondary blade number, width and length, and frond thickness at intervals of $10 \mathrm{~cm}$ along length of the blade from the intercalary meristem to eroding tip were measured (see Wing et al. 2007). Average frond thickness (mm) was used in the present analysis as a proxy for the physiological condition of E. radiata (Wing et al. 2007).

Distance to fjord entrance. For each fjord, the distance from study sites to the outer coast was calculated using a geographic information system (GIS) with $50 \mathrm{~m}$ horizontal resolution in the inner fjords. In this case, a mean coastline raster line served as a zero line for the distance algorithm 'r.cost' in GRASS 5.3 (Geographical Resources Analysis Support System; ITC-irst). r.cost used a 'knight's move' distance calculation on a square grid to accurately provide distances around complex coastlines (Neteler \& Mitasova 2002).

Data analysis. Data on stand density and morphology of Ecklonia radiata and average test diameter and density of Evechinus chloroticus were used to test relationships between variability of high-quality food with population structure and abundance of sea urchins. Accordingly, the relationship between average frond thickness $(\mathrm{mm})$ of E. radiata and stand density $\left(\mathrm{m}^{-2}\right)$ was tested using Type II linear regression. Type II linear regression was also used to test the relationship between stand density $\left(\mathrm{m}^{-2}\right)$ of E. radiata and the average test diameter ( $\mathrm{mm}$ ) of E. chloroticus. The relationship between stand density $\left(\mathrm{m}^{-2}\right)$ of E. radiata and distance $(\mathrm{km})$ from the fjord entrance was tested using linear regression. Linear regression was also used to test the relationship between density $\left(\mathrm{m}^{-2}\right)$ of E. chloroticus and distance $(\mathrm{km})$ from the entrance of each fjord.

Each time series of size frequency data was examined and significant deviations indicating mortality of the adult population were noted. Linear regression was used to test the relationship between average test diameter $(\mathrm{mm})$ and distance $(\mathrm{km})$ from the entrance of each fjord. Linear regression was also used to test the relationship between distance from the fjord entrances $(\mathrm{km})$ and the index of recruitment. These data were divided into groups of sites representing the 3 genetically distinct populations observed by Perrin et al. (2003), with the population network, Ecotype B, divided into sites from inner fjord and entrance habitats. Differences in fraction of recruits were tested using a Wilcoxon/Kruskal-Wallis test followed by multiple comparisons tests to resolve pairwise differences among these 4 groups of sites (Zar 1999).

A general linear model was used to test the relationship between average adult test diameter ( $\mathrm{mm}$ ) among years at each study site and (1) density of Ecklonia 
radiata $\left(\mathrm{m}^{-2}\right)$, as a proxy for availability of high-quality food, and (2) the recruitment index, as a proxy for the relative demographic variability in the size distribution, and (3) the interaction between recruitment index and E. radiata density. The combined model was used to assess the variability in size that could be statistically explained by these 2 variables among sites across the region. JMP version 7.0 was used for all statistical analyses.

\section{RESULTS}

Twelve of the 15 fjords were represented in the analysis with 8 fjords containing multiple sites (Fig. 2, Table 1). Type II linear regression on the relationship between average frond thickness (mm) and frond density (ind. $\mathrm{m}^{-2}$ ) of Ecklonia radiata by site demonstrated a significant positive relationship (frond thickness $[\mathrm{mm}]=2.64$ density $\left.\left[\mathrm{m}^{-2}\right]-0.13, \mathrm{R}(\mathrm{x})=0.86\right)$ (Fig. 3a) Type II linear regression testing the relationship between density $\left(\mathrm{m}^{-2}\right)$ of E. radiata and the average
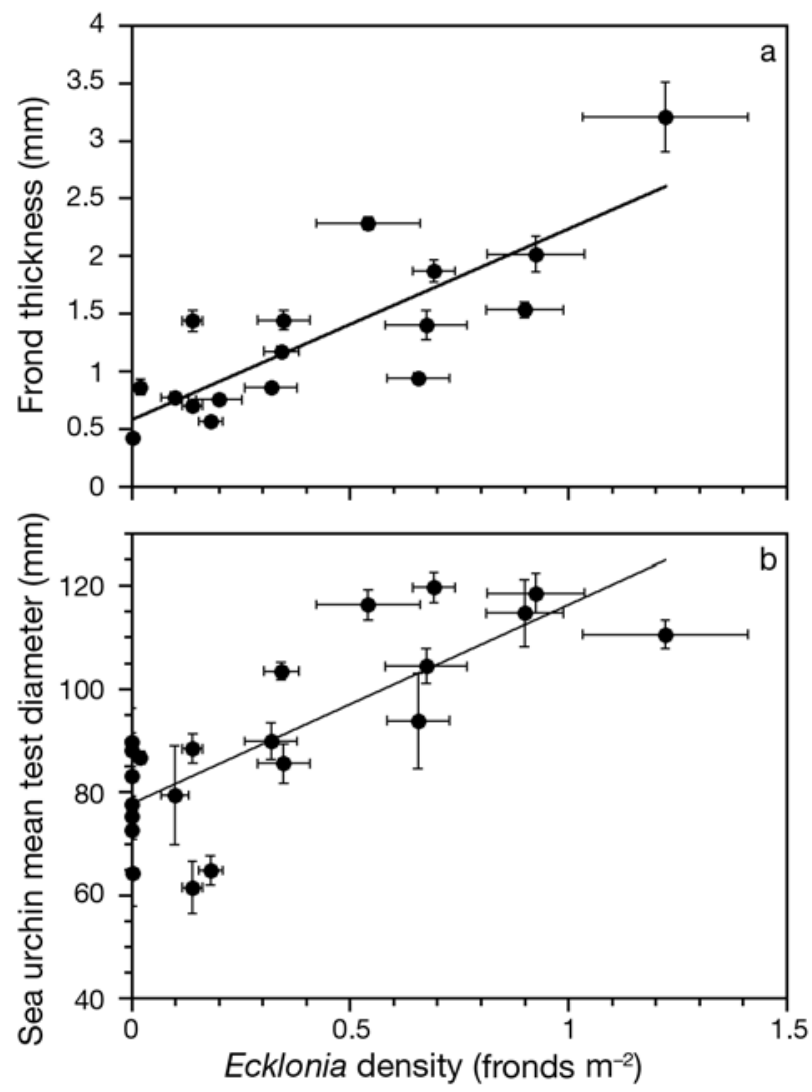

Fig. 3. Ecklonia radiata and Evechinus chloroticus. Relationship between (a) average kelp frond thickness and (b) average sea urchin test diameter and density of the common kelp. Error bars represent $\pm 1 \mathrm{SE}$

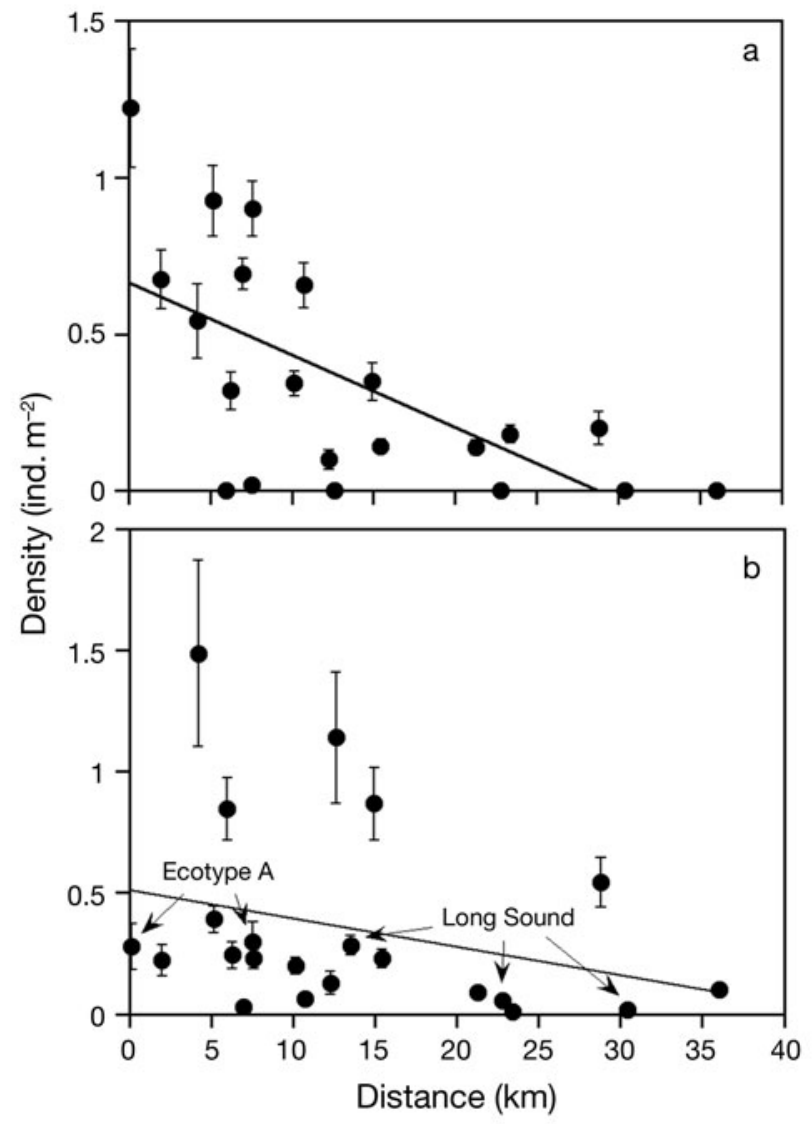

Fig. 4. Ecklonia radiata and Evechinus chloroticus. Density of (a) common kelp and (b) the sea urchin relative to distance from the fjord entrances. Error bars represent $\pm 1 \mathrm{SE}$

test diameter (mm) of Evechinus chloroticus by site indicated a significant positive relationship (test diameter $[\mathrm{mm}]=70.31+61.09$ density $\left.\left[\mathrm{m}^{-2}\right], \mathrm{R}(\mathrm{x})=0.79\right)$ (Fig. 3b).

There was a significantly higher density of Ecklonia radiata toward the entrances of the fjords (density $\left[\mathrm{m}^{-2}\right]=0.65-0.023$ distance $\left.[\mathrm{km}], \mathrm{r}^{2}=0.38, \mathrm{p}<0.002\right)$ (Fig. 4a). The relationship between density of Evechinus chloroticus $\left(\mathrm{m}^{-2}\right)$ and distance from the fjord entrance $(\mathrm{km})$ revealed no overall significant trends in abundance with distance (Fig. 4b), though highabundance sites were only found within the population network, and average abundance within the population network (Ecotype B) was higher than for the other populations across both major habitats.

Examination of time series of size distributions from the 22 survey sites revealed 5 sites with significant mortality events in the adult size distribution and colonisation by a large cohort of juveniles in subsequent surveys (Fig. 2). An example of an adult mortality event is depicted in the size distributions from Wetjacket Arm with a significant mortality observed between the 2004 and 2005 surveys (Fig. 5). 
The relationship among sites between average test diameters $(\mathrm{mm})$ and distances $(\mathrm{km})$ from the entrances of the fjords showed a pattern of large average test diameters on the outer coast and small average test

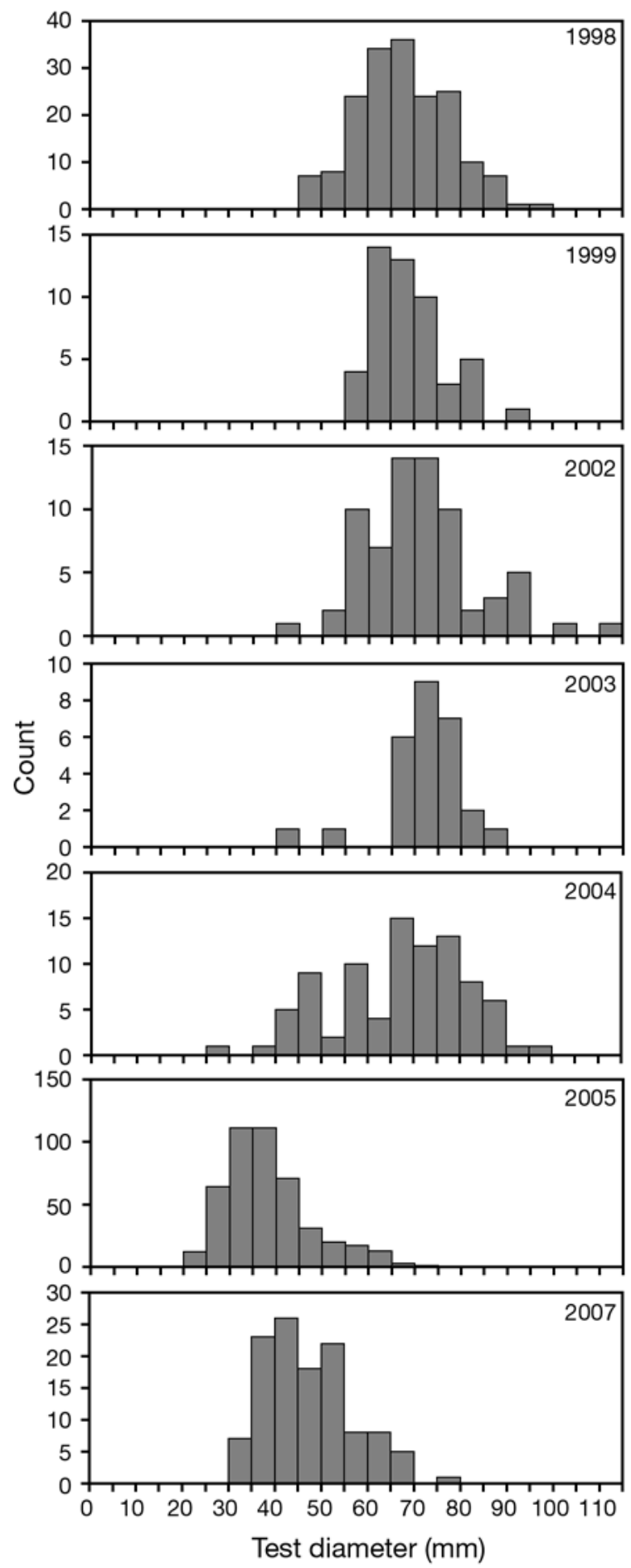

Fig. 5. Evechinus chloroticus. Time series of size distributions from Wetjacket Arm showing example of a total adult sea urchin mortality event between the 2004 and 2005 surveys
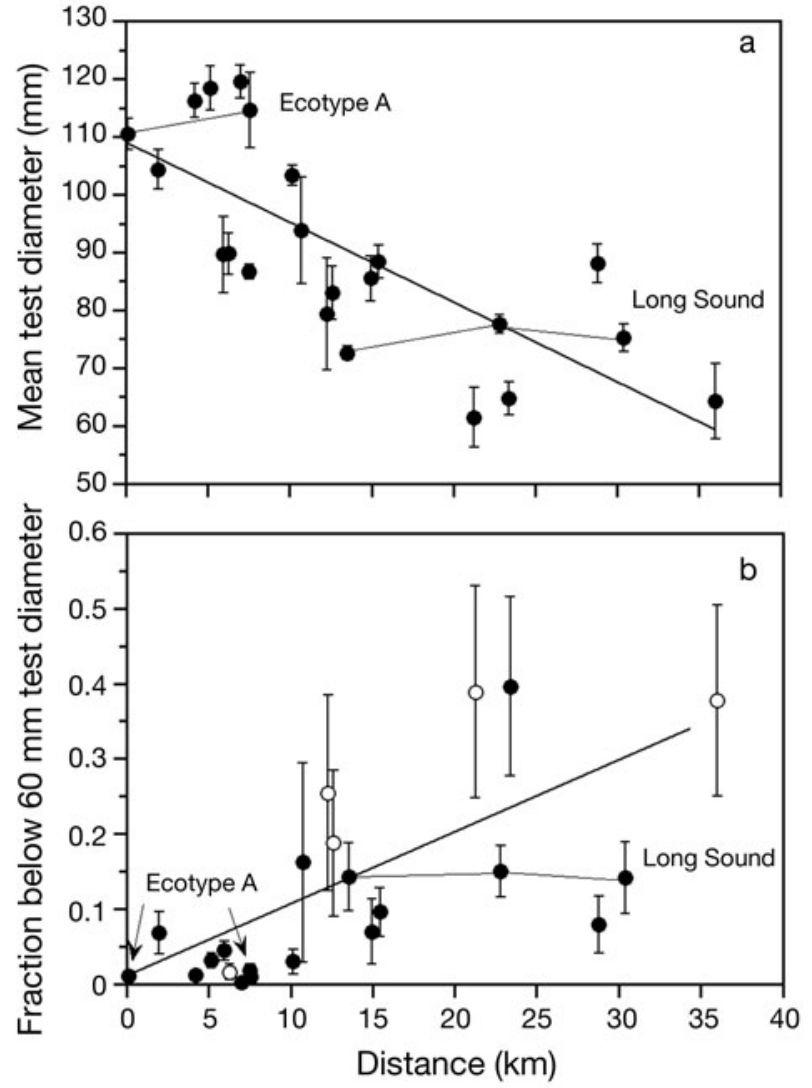

Fig. 6. Evechinus chloroticus. (a) Mean test diameter among years and (b) fraction of juveniles in population (sea urchins with $<60 \mathrm{~mm}$ test diameter) relative to distance from the fjord entrances. Error bars represent $1 \mathrm{SE}$ among years. Open symbols depict populations where adult mortality events were observed between 1998 and 2007

diameters in the inner fjords (test diameter $[\mathrm{mm}]=$ 108.9 - 1.37 distance $[\mathrm{km}], \mathrm{r}^{2}=0.55, \mathrm{p}<0.0001$ ) (Fig. 6a). Regression analysis of the relationship between the recruitment index and distance $(\mathrm{km})$ from the outer coast resulted in a significant positive relationship (recruitment index $=0.002+0.0089$ distance $[\mathrm{km}], \mathrm{r}^{2}=0.46, \mathrm{p}<0.0005$ ) (Fig. 6b). This analysis demonstrated a distinct pattern with low numbers for the recruitment index at sites near the outer coast and increased variance among sites toward the inner fjord habitats. The variance among years also increased with distance from the outer coast with a distinct trend for higher demographic variability in the inner fjord habitats. Results of the Wilcoxon/Kruskal-Wallis test for differences in the recruitment index among the genetically distinct populations identified by Perrin et al. (2003) and grouped by habitat (entrance, inner fjord) indicate significant differences (indicated below by different superscripts) among habitats within the population network $\left(\chi^{2}=10.53, \mathrm{df}=3, \mathrm{p}=0.0145\right.$, Ecotype $\mathrm{A}^{\mathrm{ab}}$, Long ${ }^{\mathrm{ab}}$, entrance ${ }^{\mathrm{b}}$, inner fjord ${ }^{\mathrm{a}}$ ) (Fig. 7). 


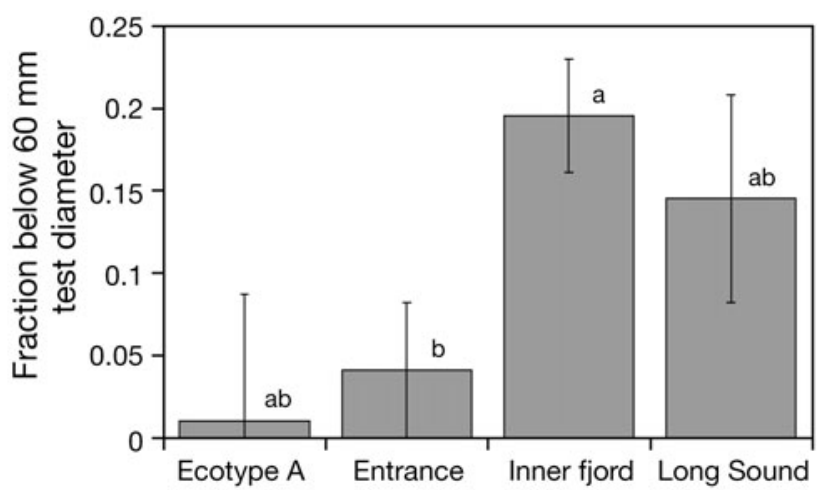

Fig. 7. Evechinus chloroticus. Average of recruitment index among sites from Ecotype A, entrance, inner fjord, and Long Sound. Error bars indicate \pm 1 SE. Groups not connected by the same letter are significantly different

Table 2. Results of a general linear model for average adult sea urchin test diameter $(\mathrm{mm})$, individuals $>60 \mathrm{~mm}$, among sites with density of Ecklonia radiata $\left(\mathrm{m}^{-2}\right)$ and the recruitment index. Summary of fit: $\mathrm{r}^{2}=0.82, \mathrm{RMSE}=7.15, \mathrm{p}<0.0001, \mathrm{n}=22$

\begin{tabular}{|lcccc|}
\hline Term & Estimate & SE & T ratio & Prob $>|\mathrm{t}|$ \\
\hline Intercept & 93.68 & 3.74 & 25.06 & $<0.0001$ \\
$\begin{array}{l}\text { Density of E. radiata } \\
\left(\mathrm{m}^{-2}\right)\end{array}$ & 23.80 & 7.52 & 3.16 & $<0.0054$ \\
Recruitment index & -60.77 & 19.20 & -3.17 & $<0.0054$ \\
$\begin{array}{l}\text { Recruit index } \times \text { Density } \\
\text { of E. radiata }\left(\mathrm{m}^{-2}\right)\end{array}$ & -19.93 & 74.32 & -0.27 & 0.79 \\
\hline
\end{tabular}

Results of combining size distributions among years and across sites reveal several distinct patterns (Fig. 8). The open population representing Ecotype A has a distinct large mode of test diameter, centred at $112 \mathrm{~mm}$ with a low proportion of individuals at smaller size classes (Fig. 8a). The portion of the population network from the entrance kelp-dominated sites has a similarly large mode with average test diameter of $105 \mathrm{~mm}$ and a moderate proportion of new recruits in the smaller size classes (Fig. 8b). The portion of the population network from the inner fjord sites has a smaller mode centred at $79 \mathrm{~mm}$ test diameter with larger and more variable proportions of newly emergent animals in the size distribution (Fig. 8c). The isolated population in Long Sound has a distinct mode centred at $75 \mathrm{~mm}$ test diameter with a large proportion of new recruits (Fig. 8d). Results of the general linear model on average test diameter among sites indicate a significant relationship, with $82.4 \%$ of the variance in average adult test diameter statistically explained by combined variability in density of Ecklonia radiata and the recruitment index (Table 2). In this combined model, the interaction between density of $E$. radiata and the recruitment
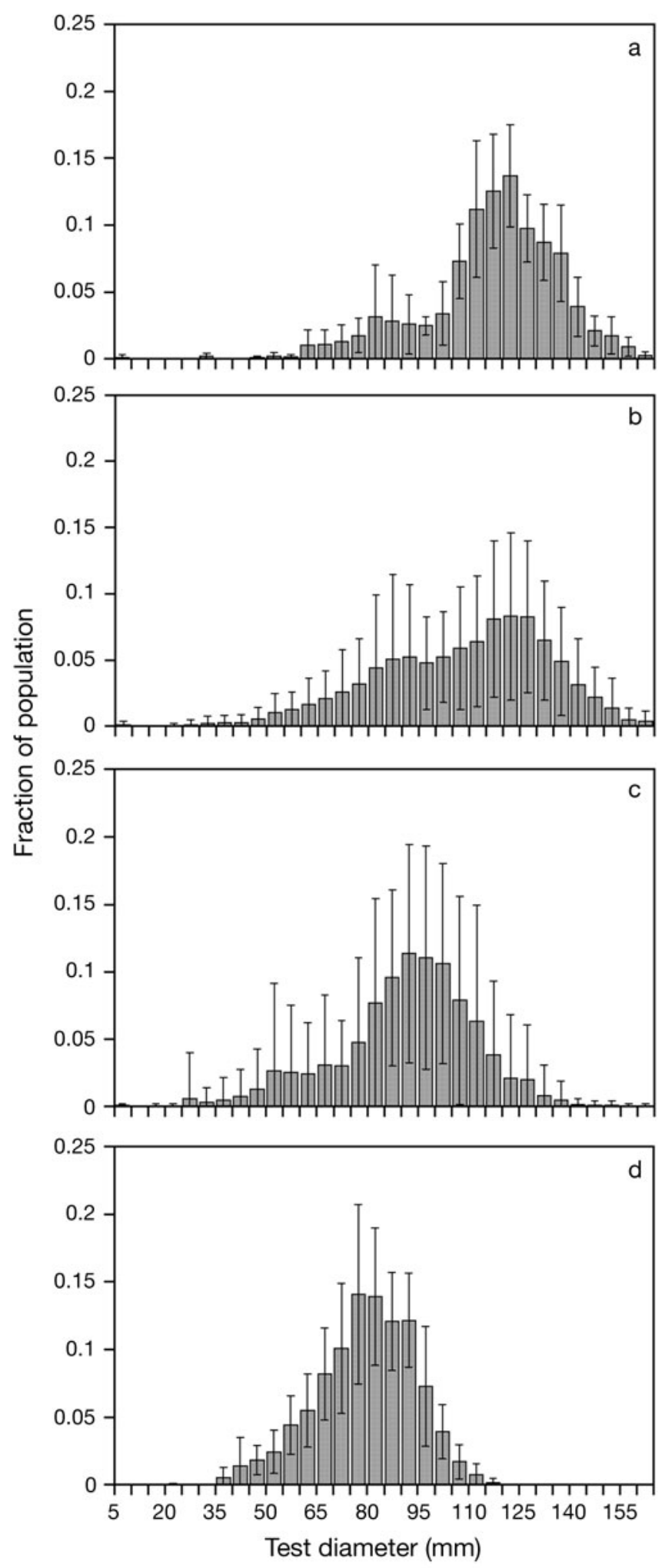

Fig. 8. Evechinus chloroticus. Long-term average size frequency of sea urchin populations from (a) Ecotype A ( $\mathrm{n}=$ 1212), (b) entrance ( $\mathrm{n}=6063)$, (c) inner fjord ( $\mathrm{n}=8632$ ) and (d) Long Sound $(\mathrm{n}=2288)$. Error bars depict $\mathrm{SE}$ among years stratified within SE among sites for each size class 
index was not significant. The recruitment index alone statistically explained $54 \%$ of the variability in average adult test diameter (adult test diameter $[\mathrm{mm}]=105.7-$ 91.8 recruitment index, $\mathrm{r}^{2}=0.547, \mathrm{p}<0.0001$ ), while density of E. radiata alone statistically explained $65 \%$ of the variability in average adult test diameter (test diameter $[\mathrm{mm}]=83.1-34.5$ density of E. radiata $\left[\mathrm{m}^{2}\right]$, $\left.\mathrm{r}^{2}=0.657, \mathrm{p}<0.0001\right)$.

\section{DISCUSSION}

The results of this study indicate that metapopulation dynamics and size structure of sea urchins in Fiordland are influenced by the effects of availability of high-quality food on adult growth and survivorship, and the effects of estuarine circulation on recruitment. The resulting strong spatial and temporal variability in population size structure distributed within each of the fjords demonstrates that populations at the fjord entrances are characterised by stable size distributions of large individuals with evidence of gradual recruitment. Populations in the inner fjord marginal habitats more regularly undergo total mortality events and recolonisation by large recruitment events. This pattern results in greater demographic variability within subpopulations in the inner fjord habitats. Further analysis of genetically distinct populations, identified by Perrin et al. (2003), indicates that the open population on the outer coast (Ecotype A) displays less demographic variability than the isolated population in Long Sound. The larger population network (Ecotype B) within the fjords has connected subpopulations displaying a range of demographic variability according to where they are located across the major habitat gradient between outer coast and inner fjord regions within each of the fjords.

Within the inner fjord habitats occupied by the population network (Ecotype B), average densities of adults are high $\left(0.35 \pm 0.12\right.$ [SE] $\left.\mathrm{m}^{-2}\right)$ relative to those in similar habitat within Long Sound $\left(0.12 \pm 0.23 \mathrm{~m}^{-2}\right)$. Similarly, average densities of adults within Ecotype A were low $\left(0.25 \pm 028 \mathrm{~m}^{-2}\right)$ relative to those in the population network in similar habitats $\left(0.49 \pm 0.15 \mathrm{~m}^{-2}\right)$. This pattern demonstrates that sites in the population network contained areas of relatively high abundance compared to those in the open and isolated populations occupying similar habitats. A comparison of the recruitment index among populations identified by Perrin et al. (2003) reveals a high recruitment index within Long Sound $(0.14 \pm 0.06)$ relative to the recruitment index in the Ecotype A population $(0.009 \pm 0.07)$. This pattern suggests different influences on demographic variability between the 2 populations, consistent with independent dynamics. Comparisons of the recruit- ment index across the remaining population network demonstrates the relatively large influence of recruitment on the size distributions of populations in the inner fjords $(0.20 \pm 0.03)$ relative to those at entrance sites $(0.04 \pm 0.04)$. There was also a high degree of demographic variability within the network related to local habitat quality, specifically the presence or absence of high-quality macroalgal food.

Density of Ecklonia radiata served as an effective proxy for the availability and quality of food for Evechinus chloroticus. E. radiata growing under conditions of light limitation, and flow-mediated limitation of mass transfer, generally have a wide and thin thallus, while in well-illuminated and wave-washed conditions, they develop a thick and relatively narrow frond (Wing et al. 2007). We observed a strong relationship between variability in morphology as indicated by frond thickness $(\mathrm{mm})$ and stand density (fronds $\mathrm{m}^{-2}$ ). Accordingly, across the wave-exposure and irradiance gradients within Fiordland (Wing et al. 2007), we observed a strong relationship between density of $E$. radiata and average test diameter of E. chloroticus, indicating the influence of food quality and availability on growth and survival of sea urchins (Lamare \& Mladenov 2000, Wing et al. 2003, 2008).

The recruitment index, fraction of the population comprising animals $<60 \mathrm{~mm}$ test diameter, was used as a proxy for the relative influence of new recruits within the size distribution. Because test diameter of adults is strongly influenced by food quality and quantity among sites (Wing et al. 2008), it is very important to base the recruitment index on newly emergent individuals. Individuals with a test diameter $<60 \mathrm{~mm}$ represent newly emergent recruits that are 3 to $4 \mathrm{yr}$ old and have been previously living under boulders and in crevices during their cryptic phase (Lamare \& Mladenov 2000). During this time they feed on algal films and drift algae and have generally depressed and consistent growth rates, as indicated by the goodness of fit of a Richard's growth function (Lamare \& Mladenov 2000). Analyses of size distributions indicate that these individuals make up transient cohorts, rather than static growth-depressed size classes within each of the habitat types. The frequency of large modes of these new recruits in size distributions reflects the dual influence of relatively high adult mortality and high larval recruitment in the inner fjords, and highlights the importance of estuarine circulation for retaining larvae within these marginal habitats.

Lamare (1998) proposed that the predominant estuarine circulation within Doubtful Sound retained distinct cohorts of Evechinus chloroticus larvae. This work was corroborated by a study of spatial variability in growth, per-capita gamete production, and larval settlement by Wing et al. (2003), which indicated a 
source-sink structure within the Doubtful Sound population. A 3-dimensional hydrodynamic model was used to test the likely source and supply of larvae within Doubtful Sound. Results indicated that populations within the inner fjords likely received a large proportion of larvae from the more productive entrance regions, and that the population was characterised by a strong reproductive source-sink structure.

Further, Wing et al. (2008) used stable isotope analysis to examine the carbon inputs to sea urchin populations along the nutritional gradient between the entrance of Doubtful Sound and the habitats at the head of the fjord, where inputs of forest litter dominate the carbon pool. Abundant kelp forests at the entrances of the fjords corresponded with high rates of assimilation of diet, particularly Ecklonia radiata, high growth rates, and large average test diameter of sea urchins. In the inner fjord habitats, these high-quality food sources were replaced with a community of estuarine algae, benthic diatoms and forest litter made available by microbial recycling. Isotopic analysis indicated that low rates of assimilation of diet in these regions corresponded with low growth rates and small average test diameters in the size distributions.

The patterns observed in the present system-wide study were consistent with these more detailed studies within Doubtful Sound. Over the 10 yr study period and across the 22 study sites there were clear relationships between quantity of Ecklonia radiata and size structure of local populations of Evechinus chloroticus. The relationship between abundance and morphological variability of $E$. radiata indicated that more waveexposed sites toward the entrances of the fjords, where conditions are less limiting for algal growth, supported a larger quantity of this high-quality food source (Wing et al. 2007, 2008). Accordingly, at sites with abundant E. radiata, populations of E. chloroticus were characterised by adult modes in their size distributions with relatively large mean test diameters $(94 \pm 9.3$ [SE] to $120 \pm 2.8 \mathrm{~mm}$ ). At sites without abundant populations of $E$. radiata in the inner fjord habitats, there were more prominent cohorts of new recruits, as indicated by the recruitment index, and there were relatively frequent total mortality events in the adult population. Causes of these mortality events, such as disease or physiological stress, may be associated with the poor nutritional status of sea urchin populations inhabiting inner fjord habitats. In the inner regions of Long Sound, which likely contains a reproductively isolated population, demographic variability was reduced. A corollary is that connectivity within the population network may result in a strong rescue effect, greater demographic variability and potential for higher average abundance for populations in the inner fjord marginal habitats, relative to abundance in reproductively isolated populations in similar habitat, such as that observed in the marine reserve in Long Sound.

These combined environmental and demographic influences on size structure of Evechinus chloroticus were reflected in the results of the general linear model for mean adult test diameter, individuals $>60 \mathrm{~mm}$ test diameter, within size distributions at the site level. Results indicated that variability in mean adult size among sites was strongly linked with a proxy for availability of abundant and high-quality food, density of Ecklonia radiata, and with a proxy for relative influence of newly emergent juveniles in the population, the recruitment index. These 2 variables statistically explained $82 \%$ of the variance in mean adult test diameter among sites.

The present data and analyses provide a rare comparison of regional-scale dynamics within a marine population network, with those in an isolated population and an open population, for a single species. Recently the Fiordland Marine Management Act 2005 established formal spatial management within this system in the form of 14 commercial exclusion zones within the inner fjord habitats for a total area of 46002 ha (59\% of inner fjord habitat) and 10 marine reserves with a total area of 10241 ha (13\% of inner fjord habitat) including the 3670 ha Te Tapuwae o Hua marine reserve comprised of Long Sound (Wing et al. 2004). The results of the present study have important implications for understanding population dynamics of sea urchins within this new spatial management scheme.

Sea urchins play a critical role in the structure of rocky reef communities and are important grazers on macroalgae and benthic invertebrates. Accordingly, their population dynamics have important consequences for maintenance of biodiversity within this system. In the context of spatial management the present study highlights the critical dependence of sea urchin subpopulation dynamics on local habitat quality and on supply of recruits from productive kelp forest habitats outside the marine reserve network (Wing et al. 2004). Because the most demographically stable and productive segments of the sea urchin population network fall outside the spatial management scheme, this leaves the regional population vulnerable to exploitation, or changes in food web structure in those outer coastal habitats. This could be partially ameliorated by inclusion of more kelp forest habitat in the marine reserve network, which would likely lead to greater stability of the regional sea urchin population, and other populations linked to kelp forest habitats (Rodgers \& Wing 2008). This system highlights the important influence of connectivity of subpopulations for maintenance of abundance and distribution across gradients in habitat quality, which has important general consequences for understanding the effects of 
spatial management of both fisheries and biological diversity within Fiordland and other coastal systems.

Acknowledgements. This work was made possible through valuable contributions on research cruises from Sara Rutger, Cecile Perrin, Kirsten Rodgers, Kim Clark, Hamish Bowman, Miles Lamare, Franz Smith, Rebecca McLeod, Mattias Sköld, Chris Cornelisen, Susan Lusseau and Nicole Goebel. Support for this research was provided from the Marsden Fund, University of Otago, Ministry for the Environment and the Department of Conservation of New Zealand.

\section{LITERATURE CITED}

Almany GR, Berumen ML, Thorrold SR, Planes S, Jones GP (2007) Local replenishment of coral reef fish populations in a marine reserve. Science 316:742-744

Choat JH, Andrew N (1986) Interactions amongst species in a guild of subtidal benthic herbivores. Oecologia 68: 387-394

> Choat JH, Schiel DR (1982) Patterns of distribution and abundance of large brown algae and invertebrate herbivores in subtidal regions of northern New Zealand. J Exp Mar Biol Ecol 60:129-162

Diehl JM, Toonen RJ, Botsford LW (2007) Spatial variability of recruitment in the sand crab Emerita analoga throughout California in relation to wind-driven currents. Mar Ecol Prog Ser 350:1-17

Dix TG (1969) Larval life span of the echinoid Evechinus chloroticus (Val.). N Z J Mar Freshw Res 3:13-16

Dix TG (1970a) Biology of Evechinus chloroticus (Echinoidea: Echinmetridae) from different localities. 3. Reproduction. N Z J Mar Freshw Res 4:385-405

Dix TG (1970b) Biology of Evechinus chloroticus (Echinoidea: Echinometridae) from different localities. 1. General. NZ J Mar Freshw Res 4:91-116

Ebert TA, Russell MP (1988) Latitudinal variation in size structure of the west coast purple sea urchin: a correlation with headlands. Limnol Oceanogr 33:286-294

Fogarty MJ, Botsford LW (2007) Population connectivity and spatial management of marine fisheries. Oceanography 20:112-123

Hixon MA, Pacala SE, Sandin SA (2002) Population regulation: historical context and contemporary challenges of open vs. closed systems. Ecology 83:1490-1508

Hughes TP, Baird AH, Dinsdale EA, Moltschaniwskyj NA, Pratchett MS, Tanner JE, Willis BL (2000) Supply-side ecology works both ways: the link between benthic adults, fecundity, and larval recruits. Ecology 81:2241-2249

Jones GP, Milicich ML, Emslie MJ, Lunow C (1999) Selfrecruitment in a coral reef fish population. Nature 402:802-804

Kritzer JP, Sale PF (2006) Marine metapopulations. Elsevier Academic Press, London

Lamare MD (1998) Origin and transport of larvae of the sea urchin Evechinus chloroticus (Echinodermata: Echinoidea) in a New Zealand fjord. Mar Ecol Prog Ser 174: 107-121

Lamare MD, Mladenov PV (2000) Modelling somatic growth in the sea urchin Evechinus chloroticus (Echinoidea: Echinometridae). J Exp Mar Biol Ecol 243:17-43
McEdward L (1995) Ecology of marine invertebrate larvae. CRC Press, Boca Raton, FL

McLeod RJ, Wing SR (2007) Hagfish in the New Zealand fjords are supported by chemoautotrophy of forest carbon. Ecology 88:809-816

Morgan SG (2001) The larval ecology of marine communities. In: Bertness M, Gaines S, Hay M (eds) Marine community ecology. Sinauer Associates, Sunderland, MA, p 159-181

Morgan LE, Wing SR, Botsford LW, Lundquist CJ, Diehl JM (2000) Spatial variability in red sea urchin (Strongylocentrotus franciscanus) recruitment in northern California. Fish Oceanogr 9:83-98

Neteler M, Mitasova H (2002) Open source GIS: a GRASS GIS approach. Kluwer Academic Publishers, Boston, MA

Pawson DL (1965) The distribution of echinoderms along the east coast of New Zealand. Trans R Soc NZ 6:245-252

Perrin CM, Roy MS, Wing SR (2003) Genetic differentiation amongst populations of the sea urchin Evechinus chloroticus and the sea star Coscinasterias muricata in New Zealand's fjords. In: Féral J, David B (eds) Echinoderm Research 2001. Balkema, Rotterdam, p 7-13

> Perrin CM, Wing SR, Roy MS (2004) Population genetic structure amongst populations of the sea star Coscinasterias muricata in the New Zealand fjords. Mol Ecol 13: 2183-2195

Rodgers KL, Wing SR (2008) Spatial structure and movement of blue cod Parapercis colias in Doubtful Sound, New Zealand, inferred from $\delta^{13} \mathrm{C}$ and $\delta^{15} \mathrm{~N}$. Mar Ecol Prog Ser 359:239-248

Sanford E, Menge BA (2007) Reproductive output and consistency of source populations in the sea star Pisaster ochraceus. Mar Ecol Prog Ser 349:1-12

Shears NT, Babcock RC (2002) Marine reserves demonstrate top-down control of community structure on temperate reefs. Oecologia 132:131-142

Underwood AJ, Keough J (2001) Supply-side ecology: the nature and consequences of variations in recruitment of intertidal organisms. In: Bertness M, Gaines S, Hay M (eds) Marine community ecology. Sinauer Associates, Sunderland, MA, p 183-200

Walker MM (1984) Larval lifespan, larval settlement, and early growth of Evechinus chloroticus (Val.). NZ J Mar Freshw Res 18:393-397

Wing SR, Gibbs MT, Lamare MD (2003) Reproductive sources and sinks within a sea urchin, Evechinus chloroticus, population of a New Zealand fjord. Mar Ecol Prog Ser 248: 109-123

Wing SR, Bowman MH, Smith F, Rutger SM (2004) Analysis of biodiversity patterns and management decision making processes to support stewardship of marine resources and biodiversity in Fiordland-a case study (Report 2 of 3). Ministry for the Environment, Wellington, New Zealand

Wing SR, Leichter JJ, Perrin CM, Rutger SM, Bowman M, Cornelisen C (2007) Topographic shading and wave exposure influence morphology and ecophysiology of Ecklonia radiata (C. Agardh 1817) in Fiordland, New Zealand. Limnol Oceanogr 52:1853-1864

Wing SR, McLeod RJ, Clark KL, Frew RD (2008) Plasticity in diet of two echinoderm species across an ecotone: microbial recycling of forest litter and bottom-up forcing of population structure. Mar Ecol Prog Ser 360:115-123

Zar JH (1999) Biostatistical analysis. Prentice Hall, Englewood Cliffs, NJ

Submitted: September 4, 2008; Accepted: December 5, 2008 Proofs received from author(s): February 27, 2009
Editorial responsibility: Lisandro Benedetti-Cecchi, Pisa, Italy 